\title{
sciendo
}

\section{RESEARCH ON THE CONCEPT OF USING CALCIUM CARBIDE AS A SOURCE OF ENERGY FOR TRANSPORT FROM THE SEABED}

DOI 10.2478/ntpe-2018-0034

\author{
Dr. Wiktor Filipek, Dr. Krzysztof Broda \\ AGH University of Science and Technology, Poland
}

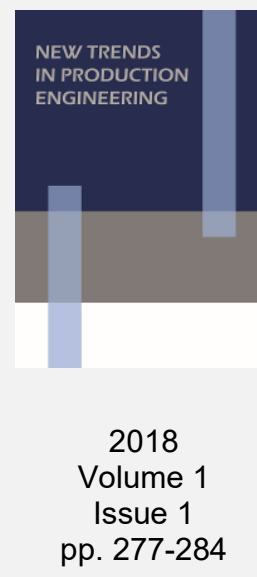

\begin{abstract}
The growing interest in the exploitation of marine deposits has resulted in the development of research on deposits and technologies for their exploitation. For several years, the authors have been dealing with one of the most important problems in the deep sea mining of mineral deposits, namely transport from great depths. This publication presents theoretical considerations regarding the use of calcium carbide as a source of energy for transport from the seabed. The authors proposed three lines of the course of the decomposition reaction of calcium carbide and then analyzed the possibility of their use. From the obtained results it can be concluded that the maximum depth of use of a simple $\mathrm{CaC}_{2}$ distribution is about $1 \mathrm{~km}$, while using the method proposed by the authors based on the "balance of forces" (using an additional medium) it is possible to apply this method to any depth occurring on Earth.
\end{abstract}

Keywords: Marine mining, transport from great depths, calcium carbide, acetylene

\section{INTRODUCTION}

In recent years, interest in the exploitation of sea deposits has been increasing (SPC, 2013), which leads to the development of research on mining and transport methods from the bottom to the surface (Karlic, 1984, Depowski, Kotliński, Rühle, Szamałek, 1998; Sobota et al, 2005; Abramowski, Kotliński, 2011; Sharma, 2017).

For several years, the authors have been researching new concepts of transport from the seabed. These works resulted in publications concerning theoretical and experimental research on the application of a new method consisting in the use of pyrotechnic materials as a source of energy in transport from the seabed from great depths (Filipek and Broda, 2016, 2017). In experimental studies, potassium nitrate and ammonium nitrate were used in a controlled pyrotechnic reaction. Three transport concepts from the seabed were also compared in terms of energy demand. In this publication, the authors focused on the possibility of using calcium carbide as a source of energy for transport of dredge spoil from the seabed. The calcium carbide (calcium acetylenate, acetylide) $\mathrm{CaC}_{2}$ (https://pubchem.ncbi.nlm.nih.gov/ compound/6352) selected by us for the experiments is commonly used in the industrial method of obtaining acetylene (Morrison and Boyd, 1997; Kaczyński and Czaplicki, 1977). We obtain it during the reaction of calcium oxide with coke at a very high temperature.

$$
\text { coke + limestone }(\mathrm{CaO}) \longrightarrow \mathrm{CaC}_{2}
$$

\section{SELECTED CALCIUM CARBIDE DECOMPOSITION REACTIONS THAT CAN BE USED IN TRANSPORT FROM THE SEABED}

The basic reaction of carbide $\mathrm{CaC}_{2}$ with $\mathrm{H}_{2} \mathrm{O}$ water found in the literature (Kaczyński and Czaplicki, 1977; Urbański, 1947) is the reaction (2) which results in acetylene $\mathrm{C}_{2} \mathrm{H}_{2}$ and calcium hydroxide $\mathrm{Ca}(\mathrm{OH})_{2}$ and generates a significant amount of energy $\Delta \mathrm{H}_{1}=-123,24$ $\mathrm{kJ} / \mathrm{mol}$. According to the first law of thermodynamics, the energy increase is positive when the energy of the system increases $\Delta \mathrm{H}>0$, and negative, when the system loses energy $\Delta \mathrm{H}<0$ (Smith, 1990). In our case, the system loses energy by releasing heat so $\Delta \mathrm{H}<0$. It is assumed that symbols in brackets: (s) - solid phase substance, (c) - substance in the liquid 
phase and $(\mathrm{g})$ - substance in the gas phase. The $\Delta \mathrm{H}_{\mathrm{n}}$ values were determined by the authors themselves on the basis of chemical tables (Mizerski, 2013) due to the fact that these values differed significantly in different publications.

$$
\mathrm{CaC}_{2(s)}+2 \mathrm{H}_{2} \mathrm{O}_{(\mathrm{c})} \rightarrow \mathrm{C}_{2} \mathrm{H}_{2(\mathrm{~g})}+\mathrm{Ca}(\mathrm{OH})_{2(s)}+\Delta \mathrm{H}_{1}
$$

One of the products of the above reaction is calcium hydroxide (slaked lime, lime lime) $\mathrm{Ca}(\mathrm{OH})_{2}$. It is an inorganic chemical compound of calcium from the group of hydroxides. It is characterized by poor solubility in water (about $1.3 \mathrm{~g} / \mathrm{dm}^{3}$ at $20^{\circ} \mathrm{C}$ ). The water solution of calcium hydroxide, which is a strong base ( $\mathrm{pH}$ around 12), is corrosive and carries the colloquial name "limestone water". It is used, among others, for detecting carbon dioxide in the presence of which the solution becomes cloudy due to the precipitation of calcium carbonate. Calcium hydroxide is widely used in technology. For deacidification of soils, it is used in a dry state, while its water solution ("milk of lime") is used as a component of mortar, for painting and in chemical processes. It forms a "lime cake" with a small amount of water. It is also used in dentistry as a component of dental cement (https://pubchem.ncbi. nlm.nih.gov/ compound/6093208).

However, the process of reaction of $\mathrm{CaC}_{2}$ calcium carbide with $\mathrm{H}_{2} \mathrm{O}$ water may proceed as the authors believe according to another path shown by dependence (3). The reaction also produces, as in reaction (2), $\mathrm{C}_{2} \mathrm{H}_{2}$ acetylene and calcium oxide $\mathrm{CaO}$. The energy of this reaction is $\Delta \mathrm{H}_{2}=-58.07 \mathrm{~kJ} / \mathrm{mol}$, which is about $47 \%$ of the energy obtained in the reaction (2)

$$
\mathrm{CaC}_{2(s)}+\mathrm{H}_{2} \mathrm{O}_{(\mathrm{c})} \rightarrow \mathrm{C}_{2} \mathrm{H}_{2(\mathrm{~g})}+\mathrm{CaO}_{(\mathrm{s})}+\Delta \mathrm{H}_{2}
$$

According to the second law of thermodynamics in spontaneous processes, the system is becoming disorderly and the necessary condition for the spontaneous reaction is the negative value of the free reaction of $\Delta G$, that is, if the system is able to work, the transformation will take place and the internal energy of the system will decrease (Smith, 1990). This condition (necessary condition) is met by reaction (2) for which $\Delta G=-87.5 \mathrm{~kJ} / \mathrm{mol}$ (Mizerski, 2013) determined on the basis of relationship (3a) is a value less than zero.

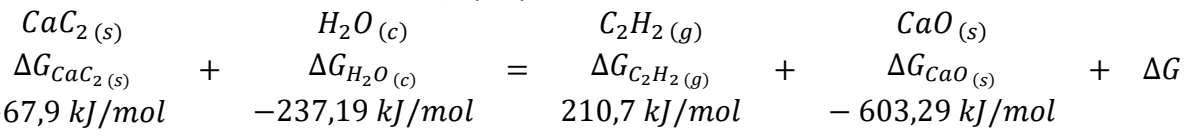

In addition, determining the entropy of the reaction $\Delta S=98.77 \mathrm{~J} /(\mathrm{mol} \mathrm{K})$ (Mizerski, 2013; Smith, 1990) according to the relationship (3b), we can determine that the analyzed reaction is spontaneous because it meets the conditions: $\Delta \mathrm{H}<0 ; \mathrm{T} \cdot \Delta \mathrm{S}>0$; the direction of the process change $\Delta \mathrm{G}(\Delta \mathrm{H}, \mathrm{T}, \Delta \mathrm{S})=\Delta \mathrm{H}-\mathrm{T} \cdot \Delta \mathrm{S}$ (Smith, 1990) is less than zero. Where $\mathrm{T}$ defines the temperature of the transformation in $\mathrm{K}$. This value is not given because regardless of its value, the criterion is met.

$$
\begin{aligned}
& \begin{array}{c}
\mathrm{H}_{2} \mathrm{O}_{(c)} \\
\Delta S_{\mathrm{CaC}_{2(s)}(s)}+\Delta S_{\mathrm{H}_{2} \mathrm{O}_{(c)}}
\end{array}+\begin{array}{c}
\mathrm{C}_{2} \mathrm{H}_{2(\mathrm{~g})} \\
\Delta S_{C_{2} \mathrm{H}_{2(g)}}
\end{array}+\Delta S_{C a O_{(s)}}+\Delta S \\
& 70,2 \mathrm{~J} /(\mathrm{mol} \cdot \mathrm{K}) \quad 69,95 \mathrm{~J} /(\mathrm{mol} \cdot \mathrm{K}) \quad 200,82 \mathrm{~J} /(\mathrm{mol} \cdot \mathrm{K}) \quad 38,1 \mathrm{~J} /(\mathrm{mol} \cdot \mathrm{K})
\end{aligned}
$$

The calcium oxide (lime) formed in the reaction (3b) $\mathrm{CaO}$ is an inorganic chemical compound belonging to the group of basic oxides containing calcium on the second oxidation state and is a white, fine-crystalline body at room temperature. It is widely used in construction, for example for mortar, in the glass and ceramic industry and in metallurgy. It is used as an insecticide (insecticide). In agriculture, it is used as a fertilizer to increase soil pH. It is also used in one of the carbide (1) methods. In laboratories, it is used as a dehydrating agent and is used to obtain ammonia (Morrison, Boyd 1997; https://pubchem.ncbi.nlm.nih.gov/compound/ 14778).

Calcium oxide has hygroscopic properties. It is bound abruptly with water to form calcium hydroxide, with heat being released. This reaction can be presented in (4). The heat generated during this process is $\Delta \mathrm{H}_{3}=-65,17 \mathrm{~kJ} / \mathrm{mol}$. It turns out that $\Delta \mathrm{H}_{1}$ according to Hess's law (Bielański, 2002; Morrison,Boyd, 1997) (heat of a chemical reaction running in a constant volume or under constant pressure does not depend on the reaction path, but only on the initial and final state) is exactly equal to the sum of energy $\Delta \mathrm{H}_{2}+\Delta \mathrm{H}_{3}$ isolated in reactions (3 and 4). It follows that the carbide decomposition process can proceed according to equation 
(3). However, if there is no calcium carbide molecule in the environment of the water molecule and there is a calcium oxide molecule, then water reacts with it:

$$
\mathrm{CaO}_{(s)}+\mathrm{H}_{2} \mathrm{O}_{(\mathrm{c})} \rightarrow \mathrm{Ca}(\mathrm{OH})_{2(s)}+\Delta \mathrm{H}_{3}
$$

The confirmation of this is another reaction (5). According to this reaction path, the carbide molecule may react with calcium hydroxide in the absence of a water molecule, resulting in the formation of acetylene and calcium oxide as a reaction product, which will eagerly react with the water if appropriate environmental conditions (humidity) calcium hydroxide occur. According to Hess's law, $\Delta \mathrm{H}_{4}$ should be equal to $\Delta \mathrm{H}_{3}-\Delta \mathrm{H}_{2}$ so if this reaction is to emerge, we have to deliver energy. After analyzing the equation (4), it turns out that $\Delta \mathrm{H}_{4}=7.1 \mathrm{~kJ} / \mathrm{mol}$ which is exactly equal to $\Delta \mathrm{H}_{3}-\Delta \mathrm{H}_{2}$.

$$
\mathrm{CaC}_{2(\mathrm{~s})}+\mathrm{Ca}(\mathrm{OH})_{2(s)} \rightarrow \mathrm{C}_{2} \mathrm{H}_{2(\mathrm{~g})}+2 \mathrm{CaO}_{(\mathrm{s})}+\Delta \mathrm{H}_{4}
$$

Let us specify at what minimum temperature the reaction may initiate (5). For this purpose, we have determined analogically, as in the case of reaction (3b), the change in entropy $\Delta S$, which is $85.32 \mathrm{~J} /(\mathrm{mol} \mathrm{K})$. Using the equation (Smith, 1990)

$$
\Delta G=\Delta H-T \Delta S
$$

Assuming $\Delta G=0$, by solving the above equation we define the minimum temperature $(T=83.21 \mathrm{~K})$, above which the theoretical reaction should begin. The obtained result shows that in sea conditions, in which we would possibly use this reaction as a source of energy in transport from the seabed, the temperature significantly exceeds the minimum temperature needed to initiate the reaction.

As a result of the above considerations, we obtain three reaction paths of calcium carbide equation (2), (3) and (5), in which the reaction product is $\mathrm{C}_{2} \mathrm{H}_{2}$ acetylene. The physical (mass, density, volume) parameters of the substrates and products discussed above for the three calcium carbide decomposition reaction paths per 1 mole produced by the acetylene reaction are shown below (Tab. 1). Analyzing the obtained results, it is difficult to conclude which of the considered reactions is the most beneficial for us as a source of energy in transport from the seabed.

Table 1.

Physical parameters of individual reaction paths.

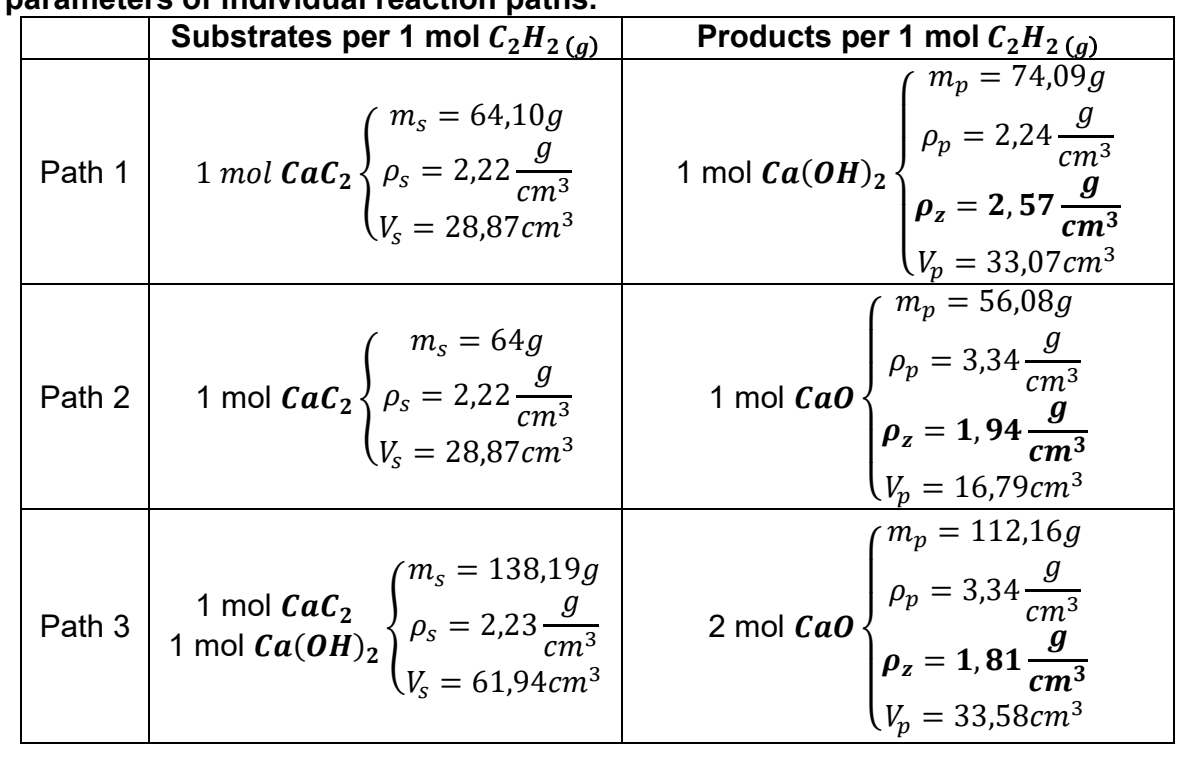

\section{DETERMINATION OF THE OPTIMAL REACTION PATH}

Let us introduce an unambiguous (empirical) criterion that would allow us to choose the most effective reaction path remembering that our considerations refer to one mole of acetylene as a reaction product. Let us analyse the situation presented in Fig. 1. The starting point is the volume of $V_{s}$ substrates, in this volume we do not take into account the water entering into the reaction as a substrate (Fig. 1a) because from our point of view it is a neutral substance. It results from the fact that the transport method under consideration (and therefore the 
reactions) takes place in the environment of the water environment. In addition, we introduce an empirical volume $V_{\alpha}$ that allows balancing the resultant force (weight minus buoyancy) of the substrates by the force of buoyancy (Filipek, Broda, 2016). So we have an empirical balance (Fig. 1a). In the case when the mass of solid reaction products (excluding gas) takes a volume smaller than $V_{s}$, we consider case $b$ ) in Fig. 1 . Then the value of the buoyancy force is determined by the empirical equivalent density determined by relationship ( 7 )

$$
\rho_{z}=\frac{m_{p}}{V_{s}}
$$

If $\rho_{z} z$ is greater than the substrate density $\rho_{s}$, the system $\left(V_{\alpha}-V_{s}\right)$ will be drowning. When $\rho_{z}=\rho_{s}$ the system remains in equilibrium, whereas when $\rho_{z}<\rho_{s}$ the system will appear.

In the next case (Fig. 1c), the mass of reaction products (excluding gas products) occupies a volume greater than the volume $V_{s}$, the reasoning line may be as before, that is, the empirical equivalent density $\rho_{z}$ determines everything.

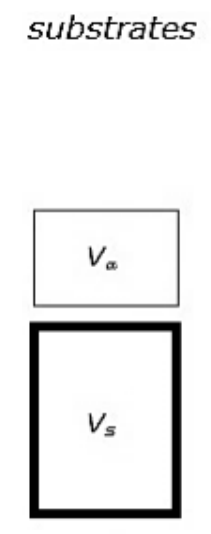

a)

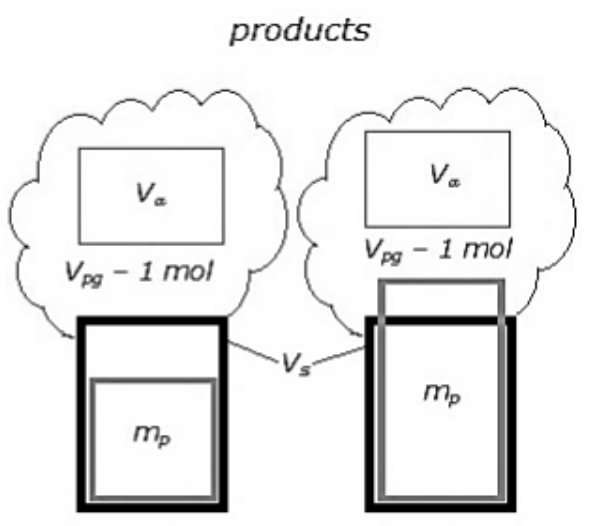

b)

c)

Fig. 1. Illustration of the idea of introducing an empirical volume $\mathbf{V}_{\alpha}$.

The dependable empirical density $\rho_{z}$, defined by (7), allows us to clearly determine which reaction path is the most beneficial for us. The calculated values of $\rho_{z}$ for individual tracks are presented in Table 1.

In the case of the first reaction, we see that $\rho_{z}$ has a value greater than the substrate density $\rho_{s}$. Therefore, we need to allocate a part of the volume from one mole of produced gas (acetylene) to balance the increase in the density of reaction products. This is due to the fact that the mass of water, which we were skipping on the substrate side, had to be included in the mass of solid reaction products of $m_{p}$. This situation does not occur with the other two reaction paths. Although - as can be seen - the density of solid reaction products $\rho_{p}$ increased, this empirical substitute density $\rho_{z}$ has a value lower than the original substrate density. Therefore, the adopted empirical $\left(V_{\alpha}-V_{s}\right)$ system will emerge. From the above-mentioned paths (2 and 3 ) the most favorable - due to the above assumptions - is path 3.

\section{ACETYLENE AND ITS PROPERTIES}

The product of the reaction in all three tracks is acetylene (ethyne) $\mathrm{C}_{2} \mathrm{H}_{2}$. It is a colourless and odourless gas, lighter than air $\rho=0.0010996 \mathrm{~g} / \mathrm{cm}^{3}\left(15^{\circ} \mathrm{C}, 1000 \mathrm{hPa}\right)$. Unfortunately, the technical product is characterized by an unpleasant odour, obtained by hydrolysis of calcium carbide, methane pyrolysis or halogen elimination. In air ( $21 \%$ oxygen) it is not completely burned due to the high percentage of carbon in the molecule (92.3\%). It is stored (in the form of a solution in acetone) in steel bottles filled with a porous mass absorbing acetone and acetylene at a pressure of $1.2 \mathrm{MPa}$ (Mizerski 2013,Urbański, 1947; https://pubchem.ncbi.nlm.nih.gov/ compound/6326). It is used in welding, in the chemical industry (eg for the production of polymers), formerly for lighting (acetylene lamp) or in medicine for narcosis (so-called narcissylene). And although it is not a "physically stifling" gas, in the case of concentrations above $50 \%$, death may occur as a result of asphyxia. However, 
as a rule, before it reaches harmful to health concentration, it explodes. Acetylene forms an explosive mixture with air of $2.4-83 \%$ by volume.

It is a substance that may under the influence of an external stimulus (eg local increase in temperature or pressure, electric discharge, etc.) violently explode into coal and hydrogen with a significant energy $\Delta \mathrm{H}_{5}=228.2 \mathrm{~kJ} / \mathrm{mol}$ in accordance with the reaction:

$$
\mathrm{C}_{2} \mathrm{H}_{2} \rightarrow 2 \mathrm{C}+\mathrm{H}_{2}+\Delta \mathrm{H}_{5}
$$

If, during the decomposition of acetylene, the products reach a temperature of $1000{ }^{\circ} \mathrm{C}$, the $\mathrm{H}_{2}$ hydrogen molecule is broken down into atoms according to the relationship (Mizerski, 2013):

$$
\mathrm{H}_{2}+\mathrm{H}_{2} \quad \overrightarrow{1000}^{\circ} \mathrm{C} 2 \mathrm{H}+\mathrm{H}_{2}
$$

Absorbing the activation energy $\mathrm{E}_{\mathrm{a}}=402 \mathrm{~kJ} / \mathrm{mol}$ it follows that a significant portion of hydrogen will decompose into atomic hydrogen in the course of rapid decomposition, which will again seek to merge into a hydrogen molecule. The result is rapid pressure surges. On an industrial scale, a controlled process of acetylene decomposition to hydrogen and coal is carried out to obtain the so-called acetylene black (https://pubchem.ncbi.nlm.nih.gov/ compound/6326). This process is carried out at an increased pressure of 4-6 bar at low temperatures.

\section{DETERMINATION OF THE MAXIMUM THEORETICAL DEPTH OF THE POSSIBLE APPLICATION OF THE REACTION}

So let us consider the process of acetylene compression neglecting its instability and determine to what pressure we can theoretically use it in the three reactions discussed, in the first case omitting $V_{\alpha}$, which balanced the weight of substrates and in the second case taking into account its impact on the process.

In the first method we are interested in the resulting parameters, i.e. $V_{p g}$ and $p$, we will mean the index 'a in the second ". Therefore, we must take an obvious assumption that the resultant density must be smaller than the density of the surrounding water without taking into account the mass of the transport module, i.e.

$$
\rho_{H_{2} O} \geq \frac{m_{p}+m_{p g}}{V_{p}+V_{p g}^{\prime}}
$$

In our considerations, we consider a mass of 1 mole of gaseous products, which for acetylene is $\mathrm{m}_{\mathrm{pg}}=26.038 \mathrm{~g}$. Therefore, the equation (10) can be transformed into a form enabling the determination of $\mathrm{V}_{\mathrm{pg}}$ :

$$
V_{p g}^{\prime} \geq \frac{m_{p}+26.038}{\rho_{H_{2} O} \mathrm{O}}-V_{p}
$$

We then receive the following values for the discussed reaction patos: $V_{\mathrm{pg}}: 67.058 \mathrm{~cm}^{3}, 65.328$ $\mathrm{cm}^{3}, 104.618 \mathrm{~cm}^{3}$.

In order to determine the maximum depth ( $p$ pressure), from which our transport module could theoretically emerge, let us check whether any of the parameters determined by us (volume $\left.V^{\prime}{ }_{p g}\right)$ is not in the supercritical area. We can do this by checking the condition:

$$
\rho_{p g}=\frac{M}{V_{p g}^{\prime}}<\rho_{k r}
$$

where $M$ is the acetylene mass of $26.038 \mathrm{~g}$ and the critical density value $\rho \mathrm{kr}$ was taken for acetylene from the tables (Mizerski, 2013) $-\rho \mathrm{kr}=0.230 \mathrm{~g} / \mathrm{cm}^{3}$. So we get in turn for three reaction paths $\rho=: 0.388 \mathrm{~g} / \mathrm{cm}^{3}, 0.399 \mathrm{~g} / \mathrm{cm}^{3}, 0.249 \mathrm{~g} / \mathrm{cm}^{3}$. We see, on the basis of the obtained values, that the medium is in a supercritical state for all reaction paths. To determine the pressure we are interested in, we will use the so-called technical Clapeyron equation (Bielański, 2002; Smith, 1990) in:

$$
n Z R T=p V \quad \Longrightarrow p=\frac{Z R T}{V_{p g}^{\prime}}
$$

The Z-factor is read from the Standing-Katz chart (http://petrowiki.org/images/7/76/ Vol1_Page_225_Image_0001.png) assuming $\mathrm{n}=1$ because we consider one mole of acetylene and the reduced temperature $T_{r}=1.05$, which corresponds to the real temperature $T$ $=\mathrm{T}_{\mathrm{zr}} \mathrm{T}_{\mathrm{kr}}=323,757 \mathrm{~K}\left(50,617^{\circ} \mathrm{C}\right)$ for $\mathrm{T}_{\mathrm{kr}}=308.34 \mathrm{~K}\left(35.2^{\circ} \mathrm{C}\right)$ (Mizerski, 2013). Adopted (Mizerski, 2013) $\mathrm{R}=8.314 \mathrm{~J} /(\mathrm{mol} \mathrm{K})$. The $\mathrm{T}$ value obtained is justified by the exothermic reaction. 
In the next steps we applied the iterative method using the Standing-Katz chart. It consisted in assuming the $p_{r}$ value at the predefined reduced temperature $T_{r}$ and reading out the searched value of parameter $Z$ from the Standing-Katz chart. Next, from equation (13) we determined the pressure $p$. On its basis we determined the value of $p r$ from the dependence $p_{r}=p / p_{k r}$ where $\mathrm{p}_{\mathrm{kr}}$ was $6.14 \mathrm{MPa}$ (Mizerski, 2013). If the difference between the assumed current and the calculated value of $\mathrm{pr}$ exceeds $5 \%$, we repeated the procedure by moving along the corresponding curve (corresponding to the temperature $T_{r}$ ) in the Standing-Katz diagram. We repeated the procedure until the assumed accuracy of $5 \%$.

On the basis of the determined pressure value $p$, we were able to determine the maximum depth $\mathrm{h}$, to which we can apply a given reaction path. The results obtained are presented in Table 2.

Table 2.

Parameters determined from the Standing-Katz chart and the maximum immersion depth for a given reaction path determined on their basis.

\begin{tabular}{|c|c|c|c|c|c|}
\hline & $\mathbf{V}_{\mathbf{p g}}^{\prime} \mathbf{1 0}^{\mathbf{6}}\left[\mathbf{m}^{\mathbf{3}} \mathbf{]}\right.$ & $\mathbf{p r}[\mathbf{1 / 1}]$ & $\mathbf{Z}[\mathbf{1 / 1}]$ & $\mathbf{p ~ [ M P a ]}$ & $\mathbf{h}[\mathbf{k m}]$ \\
\hline Path 1 & 67.058 & 1.628 & 0.249 & 9.995 & 1.019 \\
\hline Path 2 & 65.328 & 1.705 & 0.254 & 10.466 & 1.067 \\
\hline Path 3 & 104.618 & 1.341 & 0.320 & 8.233 & 0.840 \\
\hline
\end{tabular}

The table shows that, unfortunately, the maximum depth is about $1 \mathrm{~km}$, which is not enough for us. The reason for this is too much mass of solid reaction products. Determining the most efficient reaction path, we introduced in our considerations an empirical volume $\mathrm{V}_{\alpha}$, the task of which, as we have already mentioned, is to balance the weight of substrates in the solid state. In order to achieve greater depth, let's come back to this concept.

By balancing the forces acting in the second case under consideration, we can write:

$$
\left(\rho_{s}-\rho_{H_{2} O} O\right) V_{s}=\left(\frac{m_{p}+m_{p g}}{V_{p}+V_{p g}^{\prime \prime}}\right)\left(V_{p}+V_{p g}^{\prime \prime}\right)
$$

where, after multiplying on both sides by gravitational acceleration $\mathrm{g}$, the left side of the equation expresses the resultant force acting on the substrates, which are balanced by the assumed empirical force: $g\left(\rho_{s}-\rho_{\mathrm{H}_{2} \mathrm{O}}\right) V_{s}=g\left(\rho_{\mathrm{H}_{2} \mathrm{O}}-\rho_{\alpha}\right) V_{\alpha}$ having the character of buoyancy. The right side of equation (14) multiplied by $g$ expresses the resultant force acting on the reaction products. For the object in question to be in a state of equilibrium, these forces must balance each other. We determine from the equation (14) the size we are interested in $V_{p g}^{\prime \prime}$. We obtain:

$$
V_{p g}^{\prime \prime}=\frac{m_{p}+m_{p g}-m_{s}}{\rho_{H_{2}} \mathrm{O}}+V_{s}-V_{p}
$$

Analyzing the equation (15) it can be seen that if $m_{s}=m_{p}+m_{p g}$ then the expression (15) simplifies to the form:

$$
V_{p g}^{\prime \prime}=V_{s}-V_{p}
$$

When comparing equation (15) with equation (11), equation (15) can be presented in the form:

$$
V_{p g}^{\prime \prime}=V_{p g}^{\prime}+m_{s} \frac{\rho_{\mathrm{H}_{2} \mathrm{O}}-\rho_{S}}{\rho_{s} \rho_{\mathrm{H}_{2} \mathrm{O}}}
$$

Because In the considered case: $\rho_{s}>\rho_{\mathrm{H}_{2} \mathrm{O}}$ to:

$$
m_{s} \frac{\rho_{\mathrm{H}_{2} O} \rho_{S}}{\rho_{S} \rho_{\mathrm{H}_{2} O} \mathrm{O}}<0
$$

As a result, we see that $V_{p g} "\left\langle V_{p g}\right.$ ". Let us define the minimum value $V_{p g}$ " corresponding to the equilibrium state. When calculating the values of $V_{p g}$ "from equation (13), successively for reaction paths $V_{p g} "=31.828 \mathrm{~cm}^{3} ; 30.098 \mathrm{~cm}^{3} ; 28.360 \mathrm{~cm}^{3}$. In fact, for the object to emerge, $V_{p g}$ must be greater than $V_{p g}$.

For the obtained values $\mathrm{V}_{\mathrm{pg}}$ " we will determine the pressure $\mathrm{p}$ corresponding to the maximum immersion depth. In further calculations, we used, as before, the iterative method. Unfortunately, it turned out to be insufficient. The Standing-Katz chart did not cover the area of our pr range needed to determine the pressure, and hence the depth. So we determined the value of $\mathrm{V}_{\mathrm{pg}}$ " $51.6 \mathrm{~cm}^{3}$ for the maximum pr value available on the graph. For the assumed value of $p r=14.74$, we received $Z=1.735$, which corresponds to pressure $p=90.526 \mathrm{MPa}$ 
and therefore a depth of $9.231 \mathrm{~km}$. We see that the determined volume $V_{p g}$ " was greater than any of the previously determined values of $\mathrm{V}_{\mathrm{pg}}$ " for individual reaction paths. Therefore, each of the three reaction paths (in the second case) can theoretically be used as a source of energy for transport from great depths.

\section{CONCLUSIONS}

Out of the theoretical considerations in this article it appears that calcium carbide appears to be a sufficient source of energy in the process of transport from the seabed. We based our considerations on the proposed three reaction paths. The first path (2), let us call it classic path with excess water, is characterized by the fact that we allow the decomposition product of calcium carbide or calcium oxide to react with water. Due to the calculations performed, this path seems to be the least favorable due to the highest empirical substitute density among the considered reactions and the largest volume $\mathrm{V}_{\mathrm{pg}}$ ", to which we can theoretically compress acetylene.

In the second path (3) we supply water in such an amount that the calcium carbide decomposes to calcium oxide and acetylene. The amount of water should be chosen in such a way that theoretically all the water has reacted with calcium carbide and has not been left enough to react with calcium oxide. The reaction proceeding along this path according to our analysis is more effective in terms of parameters analyzed by us (empirical replacement density $\rho_{z}$, volume of gas products $V_{p g}$ 'and $V_{p g}$ ", maximum depth $h$ ).

The third track (5) is characterized by the fact that for the decomposition of acetylene carbide we do not use water taken from the environment but only calcium hydroxide. This type of reaction due to the lowest empirical replacement density and the smallest volume $V_{p g}$ " seems the most advantageous.

By determining with the use the parameter $\mathrm{V}_{\mathrm{pg}}$ ' the maximum depth of immersion, we get the value of $h$ about $1 \mathrm{~km}$. The most advantageous path is 2 where $h=1.067 \mathrm{~km}$. However, the least favorable is path 3 where $\mathrm{h}$ is $0.84 \mathrm{~km}$.

Taking into consideration $\mathrm{V}_{\mathrm{pg}}$ ", it seems that in all three cases the maximum depth of immersion is greater than the deepest place on Earth (the depth of the Challenger). However, due to the demand for acetylene, the most preferred reaction path is 3 . Path 1 is the least preferred.

However, due to the acetylene instability, it seems that the use of this medium as a source of energy causing the buoyancy force in practice will not be possible at large depths. It is true that in the literature we have not found a clear determination of the limit criterion of pressure to which we can carry out the compression, and above which the automatic decomposition occurs. We assume that it is theoretically possible to work with acetylene at high pressures, even liquefied and in a supercritical state. From a chemical point of view, we need to provide so-called activation energy. In studies related to the decomposition of acetylene, the stimulus that initiated the reaction was always given. Of course, we realize that acetylene is a very dangerous medium (Shorge et al, 2016) and in engineering and technical work the recommended pressure of compressed acetylene should not exceed 1.5 bar (https://spawalnicy.pl/edukacja/65-spawanie-gazowe-311). Of course there are other aspects limiting the use of acetylene, e.g. polymerization and addition reaction (Urbański, 1947).

From our point of view, it would be more beneficial to break down acetylene into hydrogen and carbon due to the fact that the technologies of using compressed hydrogen are known and used in industry as opposed to acetylene. This aspect is currently being studied and the results will be presented in subsequent publications. The use of hydrogen (from acetylene) with the appropriate chemical reactions will allow us in the process of ascent to bind it into compounds, which in consequence will lead to its gradual elimination as a factor that generates the buoyancy force. Otherwise, we would have to solve the problem of excess hydrogen.

The carbon formed as a result of the acetylene decomposition can theoretically be used in reaction (1) with the calcium oxide obtained according to tracks 2 and 3 to obtain a back-up energy source in the form of calcium carbide. In the case of track 1 , we would have to provide 
additional energy to break down calcium hydroxide resulting from this reaction into calcium oxide and water.

\section{ACKNOWLEDGMENTS}

This article was written within Statutes Research AGH, No. 11.11.100.005

\section{REFERENCES}

Bielański A (2002), Podstawy chemii nieorganicznej, Wydawnictwo Naukowe PWN, Warszawa.

Abramowski T., Kotliński R. (2011), Współczesne wyzwania eksploatacji oceanicznych kopalin polimetalicznych, Górnictwo i geoinżynieria, Rok 35, zeszyt 5, pp.41-61.

Depowski, S., Kotliński R., Rühle E., Szamałek K. (1998), Surowce mineralne mórz i oceanów, Wydawnictwo Naukowe Scholar, Warszawa.

Filipek W., Broda K. (2016), Theoretical foundation of the implementation of controlled pyrotechnical reactions as an energy source for transportation from the sea bed, Scientific Journals of the Maritime University of Szczecin, 48 (120), 117-124.

Filipek W., Broda K. (2017), The Theoretical Basis of the Concept of Using the Controlled Pyrotechnical Reaction Method as an Energy Source in Transportation from the Sea Bed, TransNav the International Journal on Marine Navigation and Safety of Sea Transportation, Vol.11, No. 4, 653-659.

http://petrowiki.org/images/7/76/Vol1_Page_225_Image_0001.png [Accesed 8 Feb. 2018] https://pubchem.ncbi.nlm.nih.gov/compound/6352 calcium carbide [Accesed 8 Feb. 2018] https://pubchem.ncbi.nlm.nih.gov/compound/6326 acetylene [Accesed 8 Feb. 2018]

https://pubchem.ncbi.nlm.nih.gov/compound/6093208 calcium hydroxide [Accesed 8 Feb. 2018]

https://pubchem.ncbi.nlm.nih.gov/compound/14778 calcium oxide [Accesed 8 Feb. 2018]

https://spawalnicy.pl/edukacja/65-spawanie-gazowe-311 [Accesed 8 Feb. 2018]

Kaczyński J., Czaplicki A. (1977), Chemia ogólna, Wydawnictwo Naukowo-Techniczne, Warszawa.

Karlic S. (1984), Zarys górnictwa morskiego, Wydawnictwo „Śląsk”, Katowice

Mizerski W. (2013), Tablice chemiczne, Grupa Wydawnicza Adamantan s.c., Warszawa

Morrison R.T., Boyd R.N. (1997), Chemia organiczna, Wydawnictwo naukowe PWN, Warszawa

Schorge V., Grossjohann R., Schönekess H.C., Herbst J., Bockholdt B., Ekkernkamp A., Frank M. (2016), Modeling internal ballistics of gas combustion guns, International Journal of Legal Medicine, Volume 130, Issue 3, pp 737-742

Sharma, R. (2017), Deep-Sea Mining: Resource Potential, Technical and Environmental Considerations, Springer International Publishing AG, Cham

Sobota J. et. al. (2005), Systemy i technologie wydobycia konkrecji z dna oceanów. Zeszyty Naukowe Akademii Rolniczej we Wrocławiu nr 521, Monografie XLIII, Seria: Współczesne problemy inżynierii środowiska. Wrocław

Smith E.B. (1990), Podstawy termodynamiki chemicznej, Państwowe Wydawnictwo Naukowe, Warszawa

SPC (2013), Deep Sea Minerals: Sea-Floor Massive Sulphides, a physical, biological, environmental, and technical review. Baker, E., and Beaudoin, Y. (Eds.) Vol. 1A, Secretariat of the Pacific Community, ISBN 978-82-7701-119-6, Available from: http://gsd.spc.int/dsm/public/files/meetings/ TrainingWorkshop4/UNEP_vol1A.pdf [Accesed 12 July 2015]

Urbański T. (1947), Acetylen, jako surowiec chemiczny, Przemysł Chemiczny, Vol.5, pp153164 